\title{
Autorinnen und Autoren
}

Dr. Winfried Heinemann ist Oberst a. D. und Honorarprofessor an der Brandenburgischen Technischen Universität Cottbus-Senftenberg (Platz der Deutschen Einheit 1, 03046 Cottbus); Publikationen u. a.: Unternehmen „Walküre“. Eine Militärgeschichte des 20. Juli 1944 (München 2019); Der militärische Widerstand und der Krieg, in: Jörg Echternkamp (Hrsg.), Das Deutsche Reich und der Zweite Weltkrieg, Bd. 9/1: Die deutsche Kriegsgesellschaft 1939-1945. Politisierung, Vernichtung, Überleben (Stuttgart 2004), S. 743-892; gemeinsam mit Eberhard Birk/Sven Lange (Hrsg.), Tradition für die Bundeswehr. Neue Aspekte einer alten Debatte (Berlin 2012); Die DDR und ihr Militär (München 2011); Vom Zusammenwachsen des Bündnisses. Die Funktionsweise der NATO in ausgewählten Krisenfällen 1951-1956 (München 1998).

Dr. Paul Fröhlich ist Historiker; Publikationen u. a.: „Der unterirdische Kampf“. Das Wehrwirtschafts- und Rüstungsamt 1924-1943 (Paderborn 2018); gemeinsam mit Alexander Kranz, Generäle auf Abwegen? Ludwig Ritter von Radlmaier, Adolf von Schell und die Rüstungsbürokratie des Dritten Reiches zwischen militärischer Tradition und „Neuer Staatlichkeit“, in: VfZ 64 (2016), S. 227-253; gemeinsam mit Alexander Kranz, „Ämterchaos“ in der Wehrmachtbürokratie? Das Allgemeine Heeresamt, das Wehrwirtschafts- und Rüstungsamt und die deutsche Rüstungspolitik 1938 bis 1940, in: Christian Th. Müller/Matthias Rogg (Hrsg.), Das ist Militärgeschichte! (Paderborn 2013), S. 135-155.

Dr. Barbara Manthe ist Leiterin des DFG-Forschungsprojekts „Rechtsterrorismus in der Bundesrepublik Deutschland, 1970-1990“ beim Forschungsschwerpunkt Rechtsextremismus / Neonazismus (FORENA) an der Hochschule Düsseldorf (Münsterstrasse 156, 40476 Düsseldorf); Publikationen u. a.: On the Pathway to Violence. West German Right-Wing Terrorism in the 1970s, in: Terrorism and Political Violence 2018 (online), S. 1-22; Racism and Violence in Germany since 1980,

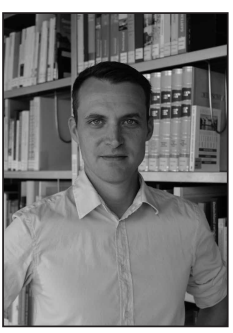
in: Global Humanities 4 (2017), S. 35-53; Richter in der nationalsozialistischen Kriegsgesellschaft. Beruflicher und privater Alltag von Richtern des Oberlandesgerichtsbezirks Köln, 1939-1945 (Tübingen 2013).

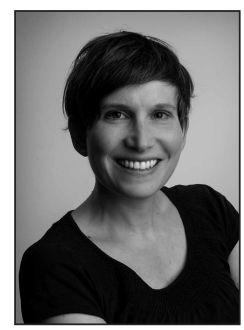




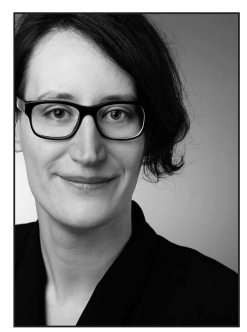

Dr. Susanne Schregel ist Wissenschaftliche Mitarbeiterin am Historischen Institut der Universität zu Köln (AlbertusMagnus-Platz, 50923 Köln); Publikationen u. a.: Social Movements, Protest, and Academic Knowledge Formation. Interactions since the 1960s, in: Moving the Social 60 (2018), S. 5-26; Interdisziplinarität im Entwurf. Zur Geschichte einer Denkform des Erkennens in der Bundesrepublik (1955-1975), in: NTM. Zeitschrift für Geschichte der Wissenschaften, Medizin und Technik 24 (2016), S. 1-37; Die „Macht der Mächtigen“ und die Macht der „Machtlosen“. Rekonfigurationen des Machtdenkens in den 1980er Jahren, in: Archiv für Sozialgeschichte 52 (2012), S. 403-428; Der Atomkrieg vor der Wohnungstür. Eine Politikgeschichte der neuen Friedensbewegung in der Bundesrepublik, 1970-1985 (Frankfurt a. M./New York 2011).

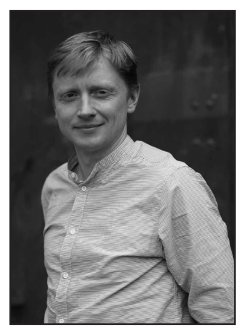

Dr. Olaf Bach ist Unternehmer, Honorarprofessor an der Weißensee Kunsthochschule Berlin (Bühringstrasse 20, 13086 Berlin) und Lehrbeauftragter an der Universität St. Gallen (Dufourstrasse 50, 9000 St. Gallen, Schweiz); Publikation u. a.: Die Erfindung der Globalisierung. Entstehung und Wandel eines zeitgeschichtlichen Grundbegriffs (Frankfurt a. M./New York 2013). 